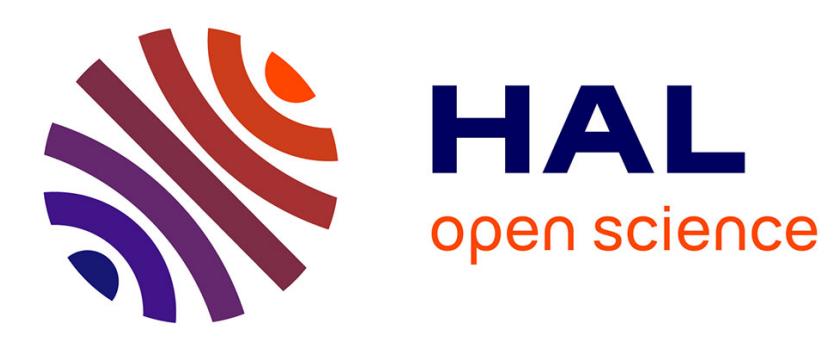

\title{
On the mechanism of the zircon-reidite pressure induced transformation
}

\author{
M. Marqués, J. Contreras-García, M. Flórez, J.M. Recio
}

\section{To cite this version:}

M. Marqués, J. Contreras-García, M. Flórez, J.M. Recio. On the mechanism of the zircon-reidite pressure induced transformation. Journal of Physics and Chemistry of Solids, 2009, 69 (9), pp.2277. 10.1016/j.jpcs.2008.04.016 . hal-00573078

\section{HAL Id: hal-00573078 \\ https://hal.science/hal-00573078}

Submitted on 3 Mar 2011

HAL is a multi-disciplinary open access archive for the deposit and dissemination of scientific research documents, whether they are published or not. The documents may come from teaching and research institutions in France or abroad, or from public or private research centers.
L'archive ouverte pluridisciplinaire HAL, est destinée au dépôt et à la diffusion de documents scientifiques de niveau recherche, publiés ou non, émanant des établissements d'enseignement et de recherche français ou étrangers, des laboratoires publics ou privés. 


\section{Author's Accepted Manuscript}

On the mechanism of the zircon-reidite pressure induced transformation

M. Marqués, J. Contreras-García, M. Flórez, J.M. Recio

PII: $\quad$ S0022-3697(08)00122-4

DOI: $\quad$ doi:10.1016/j.jpcs.2008.04.016

Reference: $\quad$ PCS 5453

To appear in: Journal of Physics and Chemistry of Solids

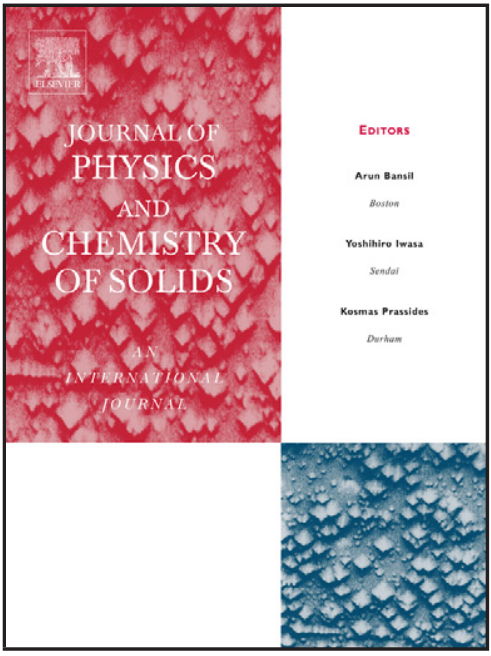

www.elsevier.com/locate/jpcs

Cite this article as: M. Marqués, J. Contreras-García, M. Flórez and J.M. Recio, On the mechanism of the zircon-reidite pressure induced transformation, Journal of Physics and Chemistry of Solids (2008), doi:10.1016/j.jpcs.2008.04.016

This is a PDF file of an unedited manuscript that has been accepted for publication. As a service to our customers we are providing this early version of the manuscript. The manuscript will undergo copyediting, typesetting, and review of the resulting galley proof before it is published in its final citable form. Please note that during the production process errors may be discovered which could affect the content, and all legal disclaimers that apply to the journal pertain. 


\title{
On the mechanism of the zircon-reidite pressure induced transformation
}

\author{
M. Marqués, J. Contreras-García, M. Flórez, and J. M. Recio \\ Departamento de Química Física y Analítica, Universidad de Oviedo, E-33006 \\ Oviedo, Spain
}

\begin{abstract}
We report first principles results of a detailed investigation directed to elucidate mechanistic aspects of the zircon-reidite phase transition in $\mathrm{ZrSiO}_{4}$. The calculated thermodynamic boundary is located around $5 \mathrm{GPa}$, and the corresponding thermal barrier, estimated from temperatures at which the transition is observed at zero and high pressure, is $133 \mathrm{~kJ} / \mathrm{mol}$. Under a martensitic perspective, we examine two different transition pathways at the thermodynamic transition pressure. First, the direct, displacive-like, tetragonal $I 4_{1} / a$ energetic profile is computed using the $c / a$ ratio as the tranformation parameter, and yields a very high activation barrier $(236 \mathrm{~kJ} / \mathrm{mol})$. Second, a quasi-monoclinic unit cell allows us to characterize a transition path from zircon $\left(\beta=90^{\circ}\right)$ to reidite $\left(\beta=114.51^{\circ}\right)$ with an activation barrier of around $80 \mathrm{~kJ} / \mathrm{mol}$ at $\beta=104^{\circ}$. This energy is somewhat lower than our previous estimation and supports the reconstructive nature of the transformation at the thermodynamic transition pressure.
\end{abstract}

Keywords: A. Oxides; C. Ab initio calculations; D. Phase transitions; D. Thermodynamic properties

Corresponding author: J. Manuel Recio. Tel.: +34985103036; fax: +34985103125.

E-mail address: mateo@fluor.quimica.uniovi.es 


\section{Introduction}

Efforts towards the classification of solid-solid transformations have identified two distinctive features as characteristic of displacive phase transitions: (i) parent and product phases exhibit a group-subgroup relationship, and (ii) cation nearest-neighbor coordination is mantained after the transition occurs. Under this perspective, one order parameter of the lower (subgroup) symmetry can be chosen to evolve continuosly from one phase to the other. In contraposition to this conception, reconstructive transformations are not directly symmetry connected and creation and/or breaking of bonds accompany the change of structure. In this respect, the zircon-reidite pressure induced phase transition in $\mathrm{ZrSiO}_{4}$ presents a paradigmatic case to study the nature of the transformation mechanism since the space group of the scheelite-type (reidite, $I 4_{1} / a$ ) lattice is a subgroup of that of zircon $\left(I 4_{1} / a m d\right)$; and the four-fold and eight-fold coordinations of, respectively, Si and $\mathrm{Zr}$ are present in both structures. In spite of this a priori displacive or distortive character, a number of experimental results points towards a reconstructive conversion for this phase transition with a volume collapse around $10 \%$ and pressurre dependent kinetic activation barriers for the direct (around $1000 \mathrm{~K}$ and $300 \mathrm{~K}$ at $10 \mathrm{GPa}$ and $20 \mathrm{GPa}$, respectively) and reverse transitions (1273 K at $0 \mathrm{GPa})$.

We have previously reported a combined experimental-theoretical work on the pressure behavior of zircon, reidite and post-scheelite phases of $\mathrm{ZrSiO}_{4}$ with special emphasis on the equations of state and the relative thermodynamic stability of these structures [1]. Here, we focus on the characterization of the zircon-reidite phase transition mechanism, $i$. e., the microscopic description of the structural, energetic and bonding changes that take place across the transition pathway connecting both structures. Our investigation allows us to determine whether the cation polyhedra $\left(\mathrm{SiO}_{4}\right.$ and $\mathrm{ZrO}_{8}$ ) involve or not the same cation-oxygen bonds in zircon and reidite, and to discriminate, based on the calculated energetic profiles, among different transition pathways.

\section{Computational details and mechanistic models}

Our electronic structure calculations have been performed following a standard planewavepseudopotential scheme under the local density approximation (LDA) of the density functional formalism, as implemented in the VASP code [2]. Details of the computational parameters and the comparison with the results provided by the generalized gradient approximation (GGA) have been previously discussed [1]. In general, presure $(p)$-volume $(V)$ points and all our energetic profiles have been computed at zero temperature and neglecting zero point vibrational contributions. Nevertheless, to account for thermal effects, we have included finite temperature contributions evaluated with a Debye-like model developed in our laboratory that only needs the static bulk modulus calculated at different pressures as input parameter [3].

Assuming that the barrier height associated with the zircon $\rightarrow$ reidite transformation depends strongly on pressure but it is negligibly affected by temperature, our Debye-like model was used 
to evaluate thermal barriers from the observed temperatures at which the zircon-reidite transformation occurs when zircon is over-pressurized or the zircon structure is recovered from reidite at zero pressure after pressure is released. The activation energy associated with the thermal barrier is the available vibrational energy of the solid (computed in this work with our Debye model) at the temperature needed to observe the direct or reverse transformation in pressure load or unload processes. We assume a linear dependence of the activation barrier on the transition pressure. This means that the activation volume, $\Delta V^{\ddagger}=V^{\ddagger}-V_{\mathrm{X}}, \ddagger$ is the transition state and $X$ is zircon or reidite, remains the same independent of the pressure at which the transition takes place. This is a reasonable assumption in analogy with the nearly constant value found at different pressures for $\Delta V=V_{\text {zircon}}-V_{\text {reidite }}$ (see also Ref. [4]). The $\Delta V^{\ddagger}=$ constant hypothesis allows us to evaluate thermal barriers at different pressures, in particular at the thermodynamic (equilibrium) zircon-reidite boundary.

The microscopic mechanism of the transition is described considering that the atoms throughout the crystal are displaced simultaneously and coherently from the zircon to the reidite structure following a transition pathway characterized by a specific space group. One transformation coordinate can be chosen to connect both structures in the same sense that a reaction coordinate monitors the mechanism of a chemical reaction. In spite of the obvious limitations, this martensitic modelization has shown to provide a valuable microscopic interpretation for many of the physical and chemical processes across phase transformations whether they display a displacive or reconstructive nature [5-8]. Here, we discuss a direct tetragonal $\left(I 4_{1} / a\right)$ pathway originated by the group-subgroup relationship between zircon and reidite, and we explore a quasi-monoclinic path as suggested by Kusaba et al. [9].

\section{Thermodynamics and thermal barriers of the zircon-reidite phase transition}

The experimental facts associated with the stability of zircon and reidite polymorphs can be summarized as follows: (i) volume collapse is around $10-11 \%$ for zircon $\rightarrow$ reidite phase transition, (ii) static experiments show that this transformation is observed at pressures in the range 10-15 GPa when temperature is increased up to 1000-1500 K [10-12], whereas at room temperature the transition is also possible if pressure is increased up to approximately 20-23 GPa [13, 14], (iii) shock wave studies found this transformation to occur very fast (microsecond time scale), and at much higher pressures (30-50 GPa) $[9,15,16]$, (iv) zircon $\rightarrow$ reidite transformation exhibits large hysteresis, zircon is not recoverable from reidite at zero pressure unless heated up to $1273 \mathrm{~K}$ [15], and (v) the thermodynamic boundary presents a positive Clapeyron slope [17].

To discuss theoretical results in relation to the above experimental data we should bear in mind the difference between our calculated equilibrium transition pressures $\left(p_{t}\right)$ and the experimental ones $\left(p_{\exp }\right)$. That the zircon $\rightarrow$ reidite transformation is kinetically hindered is obvious from 


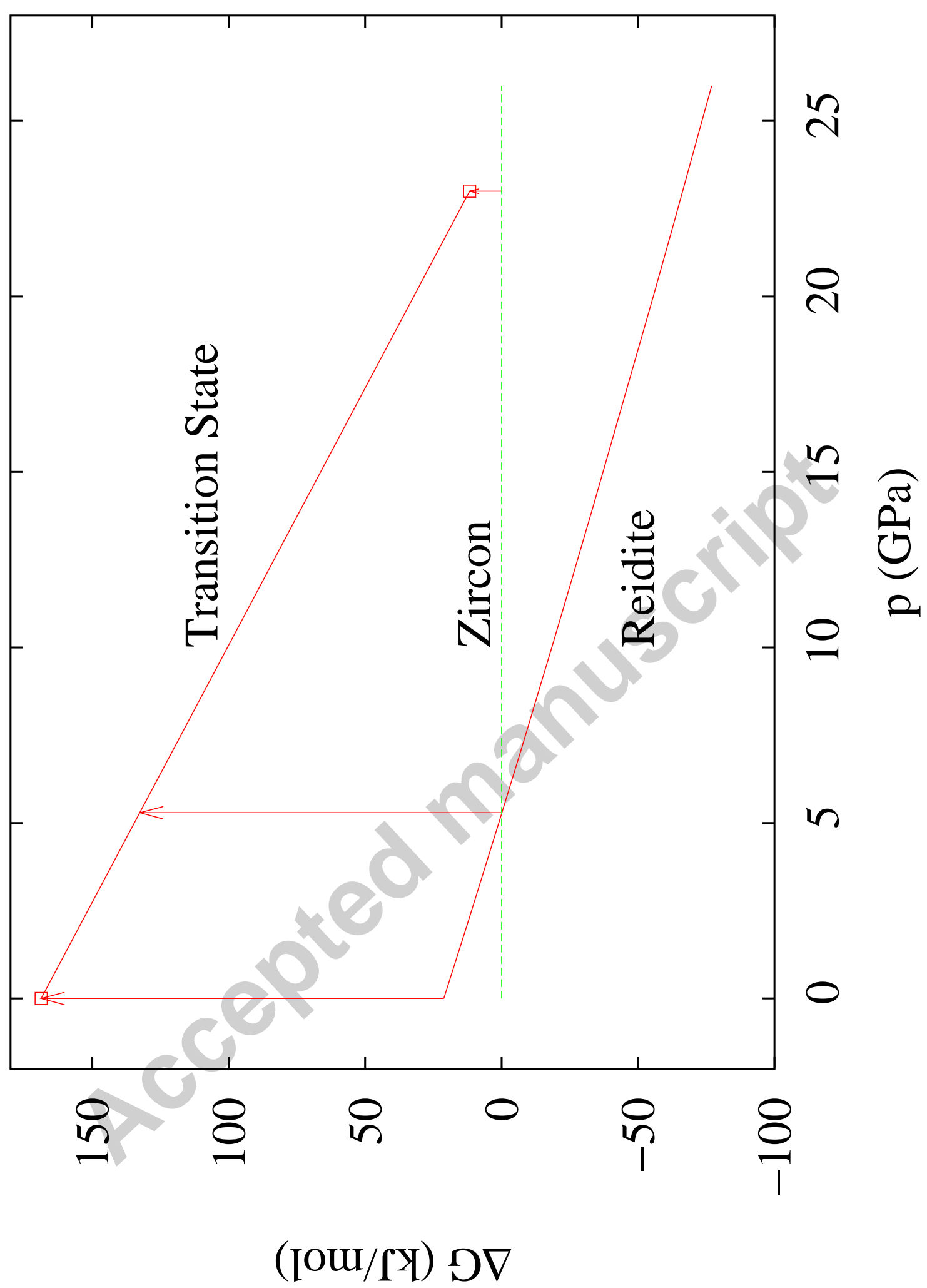

FIG. 1: Pressure dependence of the Gibbs energy $(\mathrm{kJ} / \mathrm{mol})$ of reidite relative to zircon according to present LDA calculations. Thermal barriers at 0 (reidite $\rightarrow$ zircon), $p_{t}$, and $23 \mathrm{GPa}$ (zircon $\rightarrow$ reidite) denoted by arrows and calculated using also our Debye model. 
the experimental data collected so far. Thus, when the parent and product phases are close to equilibrium, the energetic barriers associated with these transformations can be overcome only at sufficient high temperatures, and then, observed transition pressures may be compared with thermodynamic transition pressures. From the high temperature data, and assuming a positive Clapeyron slope for this transformation [13, 17], $p_{t}$ is expected to be below $10 \mathrm{GPa}$ at room temperature. Our static value of around 5.3 GPa is in concordance with this expectation and is also in good agreement with the calculated values of Crocombette and Ghaleb [18] and Farnan et al. [19]. We have also evaluated the effect of temperature in the equilibrium pressure boundary of this transformation by including vibrational energy and entropy contributions to the static results with the Debye model. We found a qualitatively satisfactory picture with Clapeyron slope slightly positive in the temperature ranges covered by our calculations since $p_{t}$ is computed to increase $1.9 \mathrm{GPa}$ from 0 to $1800 \mathrm{~K}$ for zircon $\rightarrow$ reidite transformation. This means that there is a small decrease of entropy associated to this transition, supporting the analysis of Finch and Hanchar in $\mathrm{ZrSiO}_{4}[17]$.

Under the assumption of no dependence of the barrier height on temperature, we may estimate the thermal energy in the $1000-1500 \mathrm{~K}$ range as the activation barrier for the equilibrium zircon $\rightleftharpoons$ reidite transition $[10,12]$. The validity of this analysis is illustrated by comparing the equilibrium boundary of this transformation with the experimental zircon $\rightarrow$ reidite transition pressures of Knittle and Williams (23 GPa) [13] and van Westrenen et al. (19.7 GPa) [14] obtained at $300 \mathrm{~K}$. The overpressure needed to observe the zircon $\rightarrow$ reidite transformation at $300 \mathrm{~K}$ implies that the activation energy for the direct transformation has decreased with compression [13] in such a way that the thermal energy at $300 \mathrm{~K}$ is enough to overcome the barrier. Similarly, the reidite $\rightarrow$ zircon transformation detected at zero pressure after heating up to $1273 \mathrm{~K}$ informs on the barrier height for the inverse transformation at this pressure.

A good estimation of such barrier heights is obtained by coupling the Debye model implemented in the GIBBS code [3] to our static total energy calculations. At their corresponding static equilibrium unit cells, Debye's temperatures $\left(\Theta_{\mathrm{D}}\right)$ are computed for zircon $\left(\Theta_{\mathrm{D}}^{\mathrm{z}}=796 \mathrm{~K}\right)$ and reidite $\left(\Theta_{\mathrm{D}}^{\mathrm{r}}=\right.$ $823 \mathrm{~K}$ ). The available vibrational energy for zircon at $300 \mathrm{~K}$ and $23 \mathrm{GPa}$ evaluated within our Debye model is $65 \mathrm{~kJ} / \mathrm{mol}$, whereas for reidite at $p=0$ and $1273 \mathrm{~K}$ is $194 \mathrm{~kJ} / \mathrm{mol}$. Since we are interested in the static barriers, i.e. the difference between the static Gibbs energy of zircon (or reidite) and the static Gibbs energy of the transition state, $G^{\ddagger}$, we substract the corresponding zero point energies, $53 \mathrm{~kJ} / \mathrm{mol}$ for zircon at $23 \mathrm{GPa}$ and $46 \mathrm{~kJ} / \mathrm{mol}$ for reidite at zero pressure. Applying our linear hypothesis for $\Delta G^{\ddagger}(p)$, the thermal barrier at $p_{\mathrm{t}}$ can be evaluated (see Fig. 1). The value estimated amounts $133 \mathrm{~kJ} / \mathrm{mol}$ which is equivalent (using either the vibrational energy of zircon or reidite corrected with the corresponding zero point energy) to a temperature of around $1200 \mathrm{~K}$, in the range of Ono et al. experiments [10]. 


\section{Tetragonal transition pathway}

Since the space group of reidite $\left(I 4_{1} / a\right)$ is a subgroup of that of zircon $\left(I 4_{1} / a m d\right)$, we have first chosen a $I 4_{1} /$ a common unit cell to describe the direct displacive-like mechanism of the zircon $\rightarrow$ reidite phase transition at the thermodynamic transition pressure. According to the transformation matrices shown in Table I, the lattice parameters of zircon in the $I 4_{1} /$ a common cell keep the same values as in the $I 4_{1} /$ amd unit cell $(a=b=6.545 \AA$ and $c=5.9296 \AA)$, but $\mathrm{Zr}$, Si, and O display new positions at $\left(0, \frac{1}{4}, \frac{1}{8}\right),\left(0, \frac{1}{4}, \frac{5}{8}\right)$, and $(0,0.5653,0.1946)$, respectively. For the reidite structure in the $I 4_{1} / a$ common cell, $a=b=4.696 \AA, c=10.327 \AA$, $\mathrm{Zr}$ and $\mathrm{Si}$ are in the same positions as in zircon in this cell, but O changes to $(0.2584,0.0924,0.5456)$. Using the transformation matrices in Table I, all these values can be compared with the zero pressure parameters of the corresponding conventional cells collected in Table I of Ref. [1].

The transition path may be walked using either the $\mathrm{O}$ position or the $c / a$ ratio as the transformation coordinate. For computational reasons, we have chosen $c / a$ and followed several routes including linear interpolations of the unit cell volume $\left(V_{\operatorname{lin}}\right)$ or of the lattice parameter $a\left(a_{\operatorname{lin}}\right)$, with linear variations of the $\mathrm{O}$ coordinates in both cases, while $c / a$ evolves from 0.9059 (zircon) to 2.1990 (reidite). These strategies yield unphysical large activation barriers of about $1540 \mathrm{~kJ} / \mathrm{mol}$ (see Fig. 2). A full optimization of the unit cell lattice parameters and $\mathrm{O}$ coordinates $\left(x_{\mathrm{opt}}\right)$ gives an activation barrier much lower $(236 \mathrm{~kJ} / \mathrm{mol})$, but still too high compared with our previous estimation based on the observed temperatures at which the transition is observed at zero and high pressure. These results allow us to rule out the consideration of the zircon $\rightarrow$ reidite as a displacive transformation and draw us to investigate further on the transition pathway.

\section{Quasi-monoclinic transition pathway}

Under the low symmetry $P \overline{1}$ unit cell with four formula units defined in Table I, we can study general transition paths including the two step mechanism proposed by Kusaba et al. [9]. According to these authors, the volume is reduced to the value of the reidite phase in the first step, whereas in the second step slight atomic displacements provide the final high pressure structure; and both steps may be carried out simultaneously. Using the corresponding values in their conventional unit cells, lattice parameters, cell angles and $\mathrm{Zr}, \mathrm{Si}$ and $\mathrm{O}$ atomic coordinates of zircon and reidite in the $P \overline{1}$ unit cell are easily derived using the $I 4_{1} /$ amd $(\mathrm{I}) \rightarrow P \overline{1}$ and $I 4_{1} / a$ (II) $\rightarrow P \overline{1}$ transformation matrices of Table I and noting that there are not origins shifts. In the $P \overline{1}$ cell, the positions of $\mathrm{Zr}$ and $\mathrm{Si}$, respectively, are the same in zircon and reidite whereas the sixteen oxygens have different coordinates in the two structures.

The calculation of the Gibbs energy profile, and of the structural and bonding changes across the $P \overline{1}$ pathway, is performed using the angle $\beta$ as the transformation coordinate. After a full optimization of unit cell lattice parameters and atomic coordinates, we found that $\alpha$ and $\gamma$ remains 


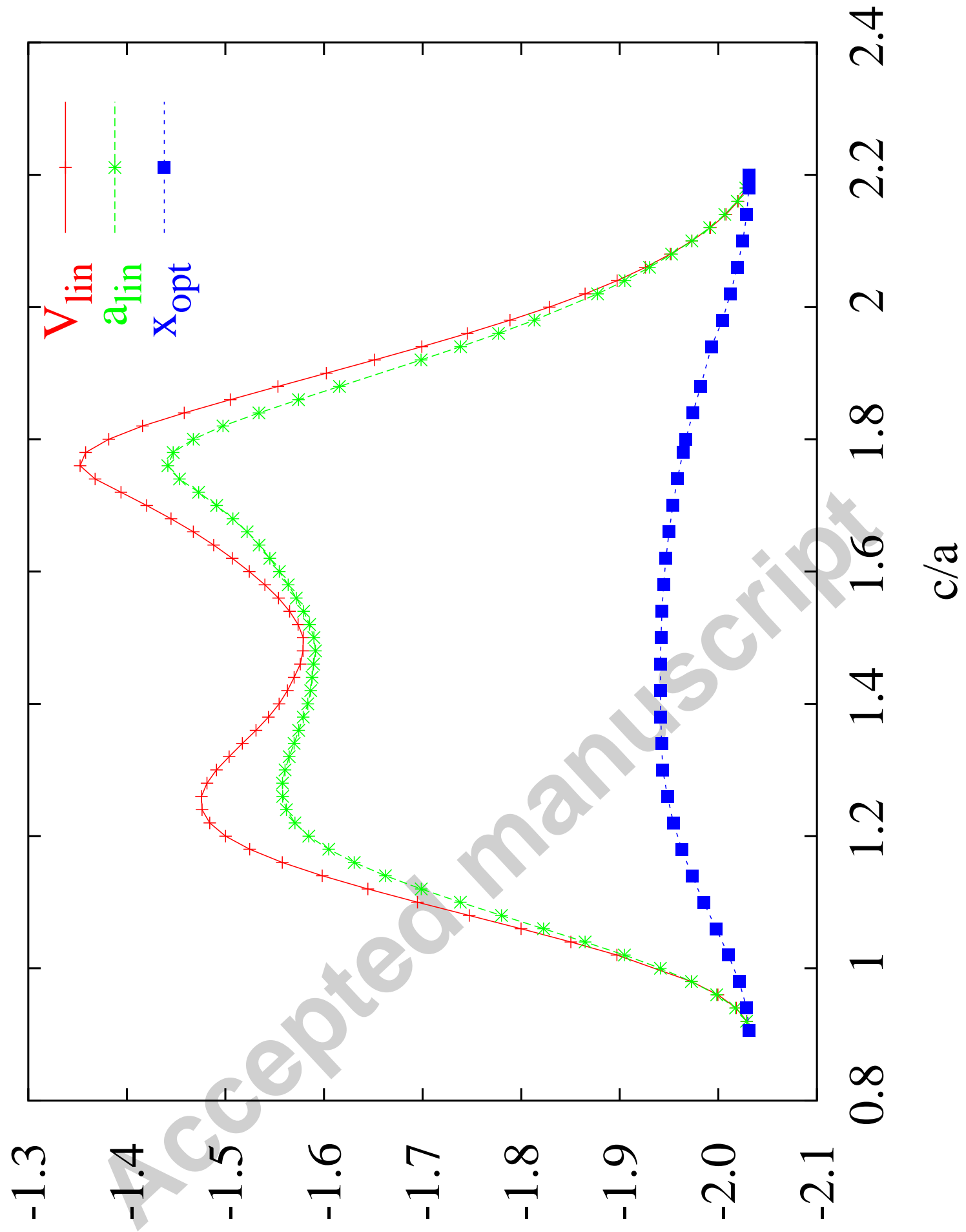

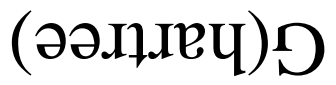

FIG. 2: Energy profile of the zircon $\rightarrow$ reidite $I 4_{1} / a$ transition path. $V_{\operatorname{lin}}, a_{\operatorname{lin}}$, and $x_{\mathrm{opt}}$ stand for different levels of calculation (see text). 
TABLE I: Transformation matrices of the lattice vectors (first row) and origin shifts (second row) associated with the pathways studied in this work. I and II stand for zircon and reidite conventional unit cells.

\begin{tabular}{|c|c|c|c|}
\hline$I 4_{1} /$ amd $(\mathrm{I}) \rightarrow I 4_{1} / a$ & $I 4_{1} / a(\mathrm{II}) \rightarrow I 4_{1} / a$ & $I 4_{1} /$ amd $(\mathrm{I}) \rightarrow P \overline{1}$ & $I 4_{1} / a(\mathrm{II}) \rightarrow P \overline{1}$ \\
\hline$\left(\begin{array}{lll}1 & 0 & 0 \\
0 & 1 & 0 \\
0 & 0 & 1\end{array}\right)$ & $\left(\begin{array}{lll}1 & 0 & 0 \\
0 & 1 & 0 \\
0 & 0 & 1\end{array}\right)$ & $\left(\begin{array}{lll}0 & 0 & 1 \\
1 & 0 & 0 \\
0 & 1 & 0\end{array}\right)$ & $\left(\begin{array}{rrr}\frac{1}{2} & 1 & \frac{1}{2} \\
-\frac{1}{2} & 1 & -\frac{1}{2} \\
-\frac{1}{2} & 0 & \frac{1}{2}\end{array}\right)$ \\
\hline$\left(0, \frac{1}{2}, 0\right)$ & $\left(0,0, \frac{1}{2}\right)$ & $(0,0,0)$ & $(0,0,0)$ \\
\hline $\begin{array}{c}a=b=a_{\mathrm{I}} \\
c=c_{\mathrm{I}}\end{array}$ & $\begin{array}{c}a=b=a_{\mathrm{II}} \\
c=c_{\mathrm{II}}\end{array}$ & $\begin{array}{c}a=c=a_{\mathrm{I}} \\
b=c_{\mathrm{I}} \\
\beta=90^{\circ}\end{array}$ & $\begin{array}{c}a=c=\sqrt{\frac{1}{2} a_{\mathrm{II}}^{2}+\frac{1}{4} c_{\mathrm{II}}^{2}} \\
b=\sqrt{2} a_{\mathrm{II}} \\
\beta=\arccos \left(\frac{1}{2} a_{\mathrm{II}}^{2}-\frac{1}{4} c_{\mathrm{II}}^{2} / \frac{1}{2} a_{\mathrm{II}}^{2}+\frac{1}{4} c_{\mathrm{II}}^{2}\right)\end{array}$ \\
\hline
\end{tabular}

close to $90^{\circ}$ while $\beta$ evolves from $90^{\circ}$ (zircon) to $114.51^{\circ}$ (reidite). Changes in the lattice parameters are smooth up to the neighborhood of the transition state where abrupt jumps occur ( $a$ and $b$ axes are interchanged), though volume follows a continuous and softer decreasing across the transition path. Concerning atomic coordinates, we found that the changes in Si and $\mathrm{Zr}$ are negligible, whereas for the oxygen crystallographic coordinates two well differentiated $\beta$ ranges of a rather constant behavior appear in the transition path enabling the location of the transition state. This behavior can be explained as due to the phase inertia associated with the high mechanical stability of the two structures, i.e., the lattice parameters and the oxygen coordinates of intermediate $P \overline{1}$ quasimonoclinic structures only suffer substantial deviations from the values in the zircon and reidite phases after $\beta$ achieves values in the middle of the transition pathway.

The transition state is situated at $\beta \simeq 104^{\circ}$, being the calculated value of the activation barrier around $80 \mathrm{~kJ} / \mathrm{mol}$. Given the approximations involved in our martensitic description of the mechanism, this value below the estimation of $133 \mathrm{~kJ} / \mathrm{mol}$ suggests the relevance of surface and/or diffusion barriers to produce the reidite structure in the laboratory, and allows us to conclude that this transition has a reconstructive character at least at the thermodynamic transition pressure.

Further support to the above conclusion is provided following the changes in the chemical bonding across the $P \overline{1}$ pathway. In the zircon structure, $\mathrm{ZrO}_{8}$ and $\mathrm{SiO}_{4}$ polyhedra alternate to form chains through edge sharing, whereas in reidite $\mathrm{ZrO}_{8}$ and $\mathrm{SiO}_{4}$ are linked by corners. Two Zr-O bonds break and two new Zr-O bonds appear in the mechanism to keep the same cation coordination in both phases. At $p_{\mathrm{t}}$, this reorganization takes place in the neighborhood of the transition state and can be associated with the increase of energy in the Gibbs energy profile. Thus, the tilting of the $\mathrm{SiO}_{4}$ tetrahedra to pass from the sharing with the $\mathrm{ZrO}_{8}$ bidisphenoid of a O-O edge in zircon to a $\mathrm{O}$ corner in reidite involves an energy barrier high enough to hinder the phase transformation at 
ambient temperature.

In summary, our investigation reveals that the thermal barrier associated with zircon $\rightarrow$ reidite phase transition is around $130 \mathrm{~kJ} / \mathrm{mol}$ at the thermodynamic transition pressure. A direct, displacive-like, transition pathway produces an unrealistic description of the transformation mechanism. If we use a low symmetry triclinic unit cell, we find a quasi-monoclinic transition path with a reasonable activation energy that explains the structural and bonding changes that take place in this phase transition and allows us to characterize it as reconstructive at least at the thermodynamic transition pressure.

\section{Acknowledgments}

Finantial support from the Spanish MEC and FEDER program under project MAT2006-13548C02-02 is gratefully acknowledged. JCG thanks the Spanish MEC for a FPU postgraduate grant. Part of this work was performed during the stay of JMR at the Laboratoire de Chimie Théorique (Université Pierre et Marie Curie, Paris) under a HPC-EUROPA grant.

[1] M. Marqués, M. Flórez, J. M. Recio, L. Gerward, and J. Staun Olsen, Phys. Rev. 74, 014104 (2006).

[2] G. Kresse and J. Furthmuller, Phys. Rev. B 54, 11169 (1996).

[3] M. A. Blanco, E. Francisco, and V. Luaña, Comput. Phys. Commun. 158, 57 (2004).

[4] M. Flórez, J. M. Recio, E. Francisco, M. A. Blanco, and A. Martín Pendás, Phys. Rev. B 66, 144112 (2002).

[5] V. P. Dmitriev, S. B. Rochal, Y. M. Gufan, and P. Tolédano, Phys. Rev. Lett. 60, 1958 (1988).

[6] M. Catti, Phys. Rev. Lett. 87, 035504 (2001).

[7] H. T. Stokes and D. M. Hatch, Phys. Rev. B 65, 144114 (2002).

[8] D. Errandonea, Europhys. Lett. 77, 56001 (2007).

[9] K. Kusaba, T. Yagi, M. Kikuchi, and Y. Syono, J. Phys. Chem. Solids 47, 675 (1986).

[10] S. Ono, Y. Tange, I. Katayama, and T. Kikegawa, Am. Mineral. 89, 185 (2004).

[11] A. F. Reid and A. E. Ringwood, Earth Planet. Sci. Lett. 6, 205 (1969).

[12] L. Liu, Earth Planet. Sci. Lett. 44, 390 (1979).

[13] E. Knittle and Q. Williams, Am. Mineral. 78, 245 (1993).

[14] W. van Westrenen, M. R. Frank, J. M. Hanchar, Y. Fei, R. J. Finch, and C.-S. Zha, Am. Mineral. 89, 197 (2004).

[15] K. Kusaba, Y. Syono, M. Kikuchi, and K. Fukuoka, Earth Planet. Sci. Lett. 72, 433 (1985).

[16] H. Leroux, W. U. Reimold, C. Koeberl, U. Hornemann, and J.-C. Doukhan, Earth Planet. Sci. Lett. 169, 291 (1999).

[17] R. J. Finch and J. M. Hanchar, in Zircon, edited by J. M. Hanchar and P. W. O. Hoskin (Mineralogical Society of America, Washington, D.C.), Reviews of Mineralogy and Geochemistry 53, 1 (2003).

[18] J. P. Crocombette and D. Ghaleb, J. Nuclear Mater. 257, 282 (1998).

[19] I. Farnan, E. Balan, C. J. Pickard, and F. Mauri, Am. Mineral. 88, 1663 (2003). 